\title{
Implementation of a Salmonella-free meat pork production system in Belgium: study plan, methods and preliminary screening results.
}

JACOB B. ${ }^{* 1}$; GROVEN B. ${ }^{~}$; FLAMENT E. ${ }^{2}$; VERSTRAETE E. ${ }^{2}$; DAUBE G. ${ }^{1}$

(1) MICROBIOLOGY LABORATORY, VETERINARY MEDECINE FACULTY, UNIVERSITY OF LIEGE, BELGIUM.

(2) INDUSTRIAL PARTNER

\section{INTRODUCTION}

Foodborne toxi-infections caused by Salmonella are widespread in industrialized countries. Nothing less than 15000 cases of human salmonellosis are detected each year in Belgium without taking into account patients treated without any diagnostic. According to the Belgian veterinary inspection services, $26.3 \%$ of pig carcasses are contaminated with Salmonella out of $11,1.10^{6}$ slaughtered pigs each year. However, Salmonella presence in pig intestinal tract doesn't entail necessarily carcass presence and human infection depends on the ingested germ number.

The objectives of this project begun in February 1999 are to obtain and especially maintain a Salmonella-free pig production system (4). Besides, implementation and standardization of surveillance methods, microbiological screening and typing should allow immediate reaction.

STUDY PLAN AND METHODS

Four major aspects are approached in the study.

The first one consists in the setting up of a questionnaire allowing to put up the situation anamnesis in terms of risk factors in the four different pig production systems. Divided into variable data collected to each visit and non variable data collected once a year, the questionnaire covers sow insemination to fattening pigs including feeding stuffs, carrying, slaughtering, cutting up and commercialization. This suggests precautions and corrective actions to consider for the surveillance plan.

To achieve an efficient surveillance plan, a reliable, sensitive but not timeconsuming method is evaluated for Salmonella detection. The commercial kit used (Probelia ${ }^{\mathrm{TM}}$ Salmonella $s p$ amplification kit, Sanofi-Diagnostic-Pasteur, France, figure 1) allow detection in 24 hours. A reference method, using the Diassalm culture media (Diagnostic Semi-Solid Salmonella agar, LAB M) (Fig.2), confirms in parallel the PCR results and isolates the strains for further characterizations.

Fig. 1: Probelia ${ }^{\mathrm{TM}}$ flowchart. Fig. 2: Reference method flowchart.
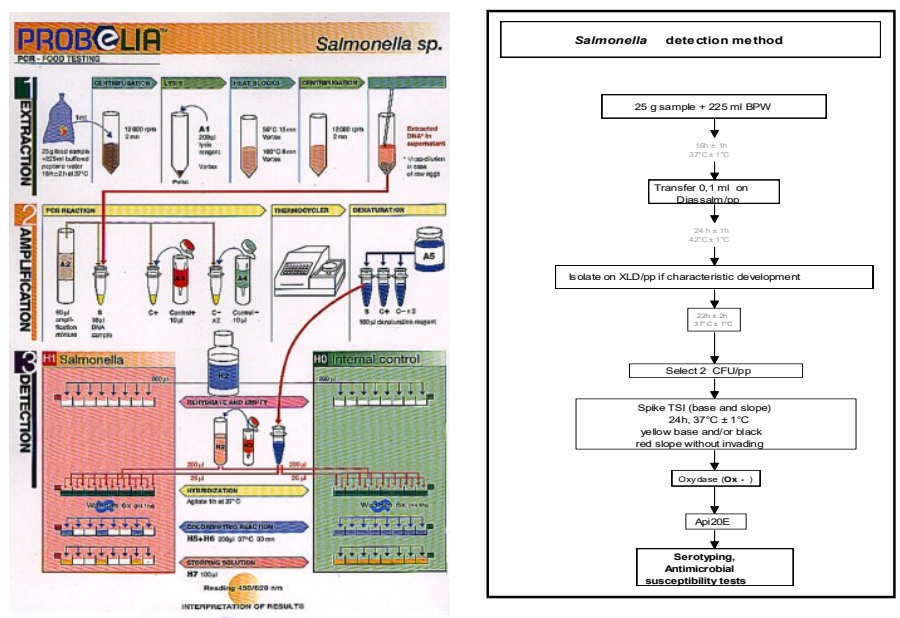

Depending on sample types (feed, faeces, waste water (before and after treatment), sludge, pig slurry, meat), optimizations must be carried out to assess inhibition problems and detection limits. Different samples of the same environment are compared to choose the best Salmonella recovery method.

Six thousand PCR tests are provided to cover the first 1.5 year surveillance period (distribution in table 1 ) on a total of $1.10^{6}$ pigs approximately.

Table 1: PCR tests distribution.

\begin{tabular}{|c|c|c|}
\hline Stage & Test number on 78 weeks (\%) & Test number / week \\
\hline Feed & $200(3 \%)$ & 3 \\
\hline Breeding & $600(10 \%)$ & 8 \\
\hline Weaning & $900(15 \%)$ & 12 \\
\hline Fattening & $700(12 \%)$ & 9 \\
\hline Slaughtering & $1980(33 \%)$ & 25 \\
\hline Cutting up & $160(3 \%)$ & 2 \\
\hline Mincing & $160(3 \%)$ & 2 \\
\hline Commercialization & $160(3 \%)$ & 2 \\
\hline Waste & $300(5 \%)$ & 4 \\
\hline Investigations after detection & $1000(16 \%)$ & 13 \\
\hline Total & 6000 & 78 \\
\hline
\end{tabular}

Nevertheless, the surveillance plan length covers a two-year period preventing seasoning variations. Samples collected every week or once every two weeks will follow piglet's life up to slaughter. Pools of five samples of the same origin are used to increase detection power and decrease costs.

Epidemiological investigations of positive samples will be achieved to trace back the contamination origin thanks to fast molecular biology methods (3) (RAPD $(1,2)$, REP-PCR, plasmid profile,...). Rapidity is of importance for intervention in the field.

Finally, all the information collected from the entire study will be transmitted to the concerned people by the way of guides and reports.

\section{RESULTS}

At the present time, the commercial kit gives rise to inhibition problems with pig slurry samples; feed sample analysis lacks of reproducibility with PCR technique. On the other hand, the reference method always provides reproducible results with a detection limit comprised between 1 and $10 \mathrm{CFU} / 25 \mathrm{~g}$ of feed and pig slurry samples.

\section{DISCUSSION}

Optimizations are necessary to get reproducible and repeatable results before using these methods in surveillance.

\section{ACKNOWLEDGEMENTS}

This work is financed by the Ministry of Small Enterprises, Traders and Agriculture, DG6- Research and Development division and by the Ministry of Walloon Country.

\section{REFERENCES}

1. Hilton A.C., J.G. Banks and C.W. Penn. 1997. Optimization of RAPD for fingerprinting Salmonella. In Letters in Applied Microbiology, $24: 243-248$.

2. Hilton A.C., J.G. Banks and C.W. Penn.. 1996. Random amplification of polymorphic DNA (RAPD) of Salmonella : strain differentiation and characterization of amplified sequences. In Journal of Applied Bacteriology, 81: 575-584.

3. Schwarz S., M. Weide-Botjes, B. Kobe and G. Frech. 1997. Molecular methods for the epidemiological analysis of Salmonella serovars of zoonotic importance. In Salmonella and Salmonellosis Proceedings, CNEVA, Communications and Posters, Ploufragan (F) May 20/21/22, 41-44.

4. Wray C. and R.H. Davies. 1997. Reflection on the epidemiology of Salmonella : a challenge for disease control. In Salmonella and Salmonellosis Proceedings,

CNEVA, Communications and Posters, Ploufragan (F) May 20/21/22, 309-314.

*Corresponding author address: Sart-Tilman, Bât. B43bis; B-4000 LIEGE; BELGIUM B.Jacob@ulg.ac.be 